INPLASY

PROTOCOL

To cite: Jaradat et al. Seasonal Variation Effects on Perforated Peptic Ulcer- A systematic

Review. Inplasy protocol 202110096. doi:

10.37766/inplasy2021.1.0096

Received: 26 January 2021

Published: 26 January 2021

Corresponding author:

Ihab Jaradat

ihab.jaradat@yu.edu.jo

Author Affiliation:

Yarmouk University

Support: None.

Review Stage at time of this submission: Data analysis.

Conflicts of interest:

None.

\section{Seasonal Variation Effects on Perforated Peptic Ulcer - A systematic Review}

Review question / Objective: Is there a seasonal effect on perforated peptic ulcer?

Condition being studied: Perforated Peptic Ulcer.

Information sources: PubMed, Web of Science, Google Scholar, CrossRef.

INPLASY registration number: This protocol was registered with the International Platform of Registered Systematic Review and Meta-Analysis Protocols (INPLASY) on 26 January 2021 and was last updated on 26 January 2021 (registration number INPLASY202110096).

\section{INTRODUCTION}

Review question / Objective: Is there a seasonal effect on perforated peptic ulcer?

Condition being studied: Perforated Peptic Ulcer

\section{METHODS}

Participant or population: Admitted cases of perforated peptic ulcer.

Intervention: Seasonal effect on admission rate.
Comparator: Season of admission.

Study designs to be included: Cohorts.

Eligibility criteria: (1) Written in English language (2) Conducted on more than 1year period (3) Collected data defined the time of perforation in weeks, months, or seasons (4) Review articles, theoretical papers, and audits were excluded.

Information sources: PubMed, Web of Science, Google Scholar, CrossRef. 
Main outcome(s): The effect of seasonality upon peptic ulcer perforation.

Quality assessment / Risk of bias analysis: All included studies were assessed for quality using the Newcastle-Ottawa Scale (NOS).

Strategy of data synthesis: A systematic, thorough literature search was performed by two authors independently by applying the search keywords and search algorithm of - Perforated AND (Gastric ulcer OR Duodenal ulcer OR Peptic ulcer OR PUD) AND (Fall OR Spring OR Autumn OR Winter OR Periodicity OR Climate) - on the databases (Google scholar, PubMed, Web of Science, and CrossRef) and without time limitations, to insure the best use of all available published data. Search results were obtained both manually and by using the software Publish or Perish 7.

Subgroup analysis: N/A.

Sensitivity analysis: N/A.

Language: English.

Country(ies) involved: Jordan.

Keywords: Seasonal variation, PPU, Peptic ulcer perforation, Periodicity.

Contributions of each author:

Author 1 - Ihab Jaradat - Initiated the study, Provided Supervision, contributed to study concept and design and identied and acquired reports of trials and extracted data.

Email: ihab.jaradat@yu.edu.jo

Author 2 - Sarah Al Sharie - contributed to study concept and design and identied and acquired reports of trials and extracted data and contributed to the interpretation of the data and drafted the manuscript and critically reviewed the manuscript.

Email: sarahalsharie2000@gmail.com

Author 3 - Raed Ennab - Drafted the manuscript.

Email: Raed.ennab@yu.edu.jo

Author 4 - Sohaib Al-Omari - critically reviewed the manuscript.

Email: sohaibalomary.sa@gmail.com 